\title{
Human urokinase, a serine proteinase, potentiates the in-vitro growth of micro-organisms which commonly infect burn patients
}

\author{
D. A. HART and D. E. WOODS
}

Department of Microbiology and Infectious Diseases, University of Calgary Health Sciences Centre, Calgary, Alberta T2N 4N1, Canada

\begin{abstract}
Summary. Addition of human urokinase, a serine proteinase, to in-vitro cultures of Pseudomonas aeruginosa strain M2 enhanced bacterial growth. The enhancement of growth depended on the dose of urokinase (10-12500 units) and the enzymic activity of the protein. Other mammalian proteolytic enzymes (trypsin, chymotrypsin, polymorphonuclear leucocyte elastase, thrombin and plasmin) tested did not affect bacterial growth in vitro. Experiments with clinical isolates of Candida albicans, Klebsiella pneumoniae and Staphylococcus aureus from burn patients indicated that urokinase could enhance the in-vitro growth of all of these micro-organisms. However, some strain-to-strain variation was noted in the extent of this enhancement. These results indicate that urokinase, which could be released into burn injury sites from either damaged tissues or inflammatory cells, is capable of enhancing the growth of several micro-organisms that commonly infect patients with thermal injuries, particularly under oxygen-limited conditions and when few micro-organisms are present.
\end{abstract}

\section{Introduction}

Burn injuries affect a large number of individuals each year. Patients with third degree burns are at risk from life-threatening infections which develop in a significant proportion of them, even though advances in antibiotic therapy and the nutritional treatments of such patients have been made over the past few decades. ${ }^{1-5}$ Such infections are usually caused by opportunist organisms such as Pseudomonas aeruginosa, Candida albicans, Klebsiella pneumoniae and Staphylococcus aureus. ${ }^{3,4}$ These micro-organisms may infect burn victims through the wound site, or possibly via the gastrointestinal tract. ${ }^{6,7}$ The susceptibility of such patients to infection by these organisms is believed to be due to multiple factors. ${ }^{1-5}$

The response of host defence systems to thermal injuries has been studied extensively both in man and in animal models. ${ }^{1-3,5,8-13}$ From such studies, it is apparent that after thermal injury the function of macrophages and polymorphonuclear leucocytes is compromised. These cellular defects probably contribute to the dissemination of infection in burn patients, because their phagocytosis and killing mech- anisms have been rendered ineffective by the injury. In addition to cellular regulation, burn patients also exhibit alterations in the regulation of many of the plasma protein cascades, such as coagulation, complement and fibrinolysis. ${ }^{14-17}$ Such disruption not only contributes to a loss in the effectiveness of these host defence systems, but their inappropriate activation can also lead to the generation of several proteolytic enzymes that can damage tissues.

Several groups of workers have characterised the microbial virulence factors associated with the ability to colonise and infect animals with thermal injuries. ${ }^{9,10,18}$ In particular, emphasis has focused on pseudomonads, as they are a major pathogenic group in this patient population. ${ }^{1-5}$ Several reports have implicated elastase and alkaline protease as important virulence factors in burns. ${ }^{8,9,18-21}$ Strains defective in proteinase production are considerably less virulent than their counterparts..$^{9,10,21,22}$ The basis for this protease-dependent virulence is not completely understood. However, there is evidence ${ }^{8-10,18,19,21-23}$ that the bacterial proteinases interact with host proteolytic cascades to generate additional activities that are important in the infection process. Interestingly, injection of burned mice with proteinase inhibitors can protect the animals from infection. As some of the inhibitors that are effective in this regard do not inhibit 


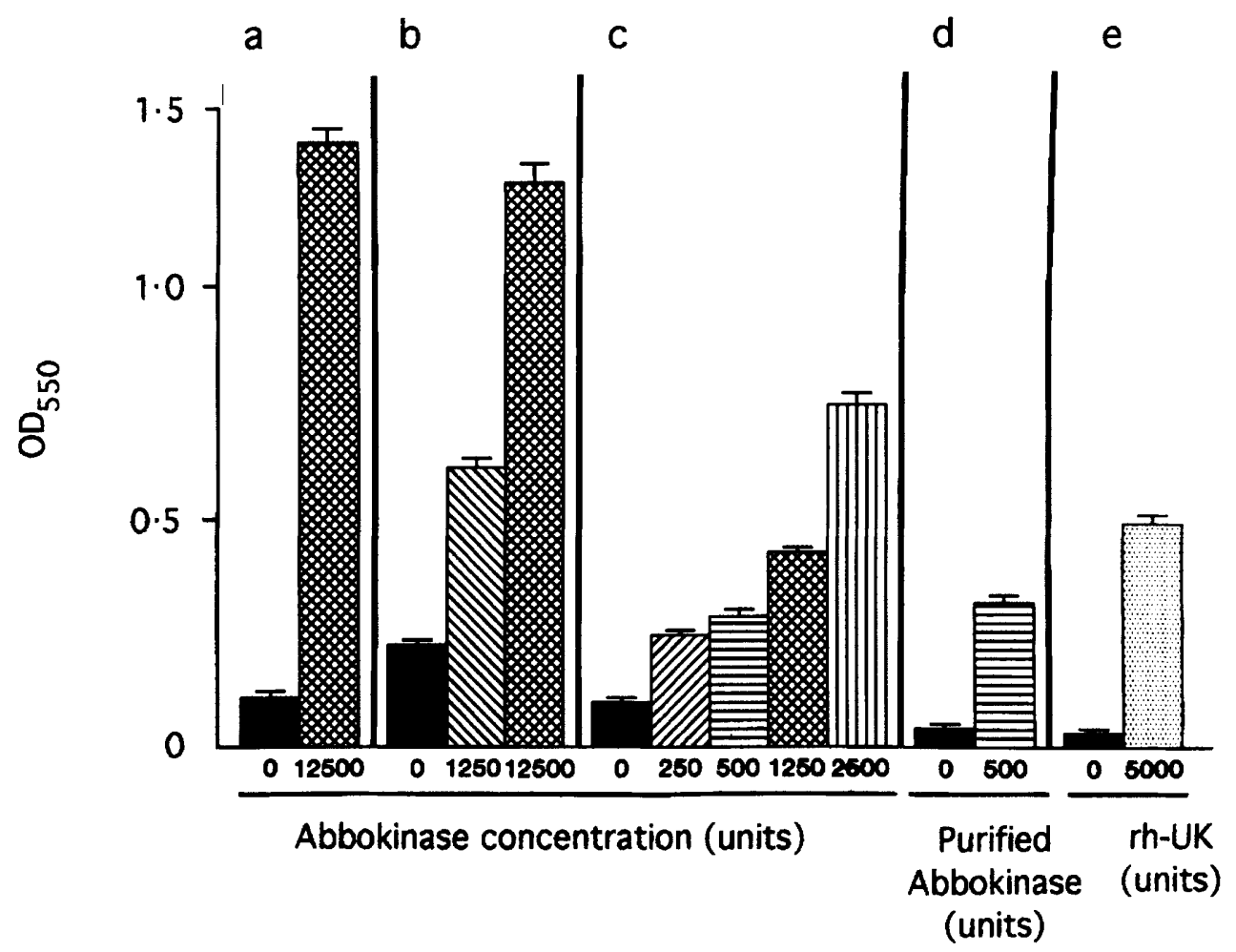

Fig. 1. Enhancement of the growth of $P$. aeruginosa strain M2 by UK. Strain M2 was cultured for $24 \mathrm{~h}$ at $37^{\circ} \mathrm{C}$ in $\mathrm{M} 9$ in the absence or presence of the indicated concentrations of UK (panels a, b,, , three separate experiments), affinity purified UK (panel d) or rh-UK (panel e). The OD 55 was determined for triplicate samples at each point and the indicated values represent the mean and SD.

a

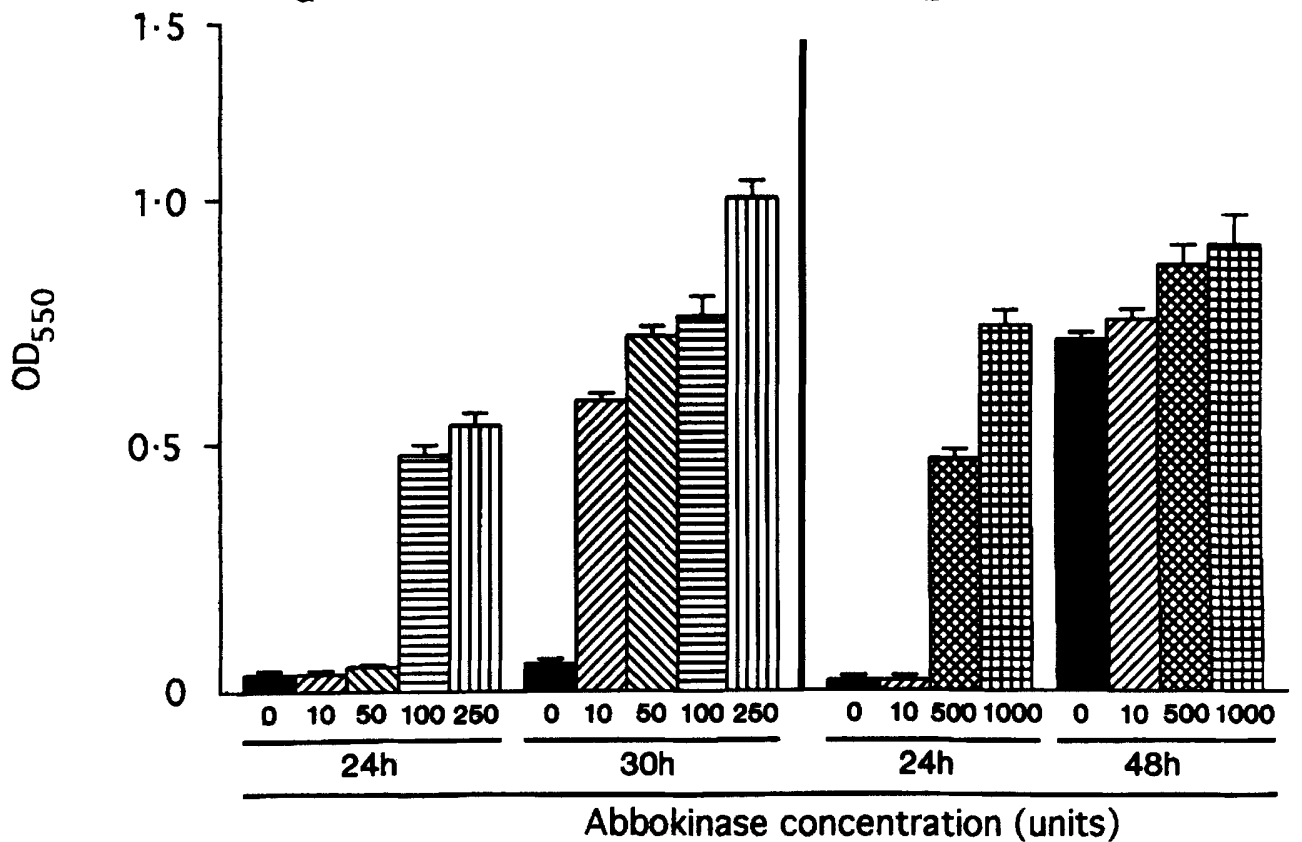

Fig. 2. Time dependence of the enhancement of strain M2 growth by low dose UK. Triplicate cultures of $P$. aeruginosa strain M2 were grown in $\mathrm{M} 9$ for the indicated times at $37^{\circ} \mathrm{C}$ in the absence or presence of UK. The indicated values represent the mean $\mathrm{OD}_{550}$ and $\mathrm{SD}$ of the cultures.

the pseudomonal proteinases, it has been concluded that host enzymes are involved. ${ }^{10,22,23}$ In particular, proteinases of the activation cascades, such as Hageman factor activation, kinin generating enzymes and the coagulation (e.g., thrombin) and fibrinolytic (e.g., urokinase and tissue plasminogen activator) systems, are potential sources of the proteinases which appear to contribute to the infectious process. ${ }^{8-10.18 .21}$ Holder and Neely ${ }^{21.22}$ postulate that the activation of host proteinase systems (e.g., Hageman factor ac- 
tivation) contributes to infection via an effect on the immune system, whereas others have shown that the pseudomonal elastase-induced activation of the Hageman factor system may contribute to the shock response of the host. ${ }^{20}$

However, the mechanisms by which the host proteinases implicated in the infectious process could potentiate infection have not been completely elucidated. The effects of the proteinases on the organisms involved could be indirect, as indicated above, or they could be direct. This study examined whether urokinase (UK), a plasminogen activator that can be released from damaged cells and from inflammatory cells, ${ }^{24-27}$ could stimulate directly the in-vitro growth of micro-organisms that commonly infect burns.

\section{Materials and methods}

\section{Microbial strains}

The M2 strain of $P$. aeruginosa has been well characterised, particularly in the burned mouse model. ${ }^{28,29}$ The following blood isolates from burn patients were obtained from Dr A. McManus (Fort Sam, Houston, TX, USA): S. aureus (920712002, 920919001, 930105001, 930121001 and 930319033) which were designated SA-1-SA-5, respectively; $K$. pneumoniae (901021001, 910405002, 910621003, 920401002 and 920909003) which were designated KP-1-KP-5, respectively; C. albicans (901030001, 910213002, 910407002, 920412040 and 920423001) which were designated CA-1-CA-5, respectively. Nonmucoid variants of $P$. aeruginosa (strains $\mathrm{PAO}$ and DG-1), were those used previously ${ }^{30}$ and $P$. aeruginosa strain 44.821 was isolated from the sputum of a patient with cystic fibrosis.

\section{Reagents}

Low-mol. wt human urokinase (Abbokinase; UK) and recombinant human urokinase(rh-UK) were supplied by Abbott Laboratories (Abbott Park, IL, USA). For some experiments, the UK was further purified by affinity chromatography on benzamidineagarose (Pierce Chemical Co.). Diisopropyl fluorophosphate(DFP)-inactivated UK was prepared by incubating the enzyme in $5 \mathrm{mM}$ DFP followed by dialysis. ${ }^{31}$ The enzyme was $>98 \%$ inactivated by this procedure. Casamino acids were obtained from Difco Laboratories. Thrombin, chymotrypsin, trypsin, PMN elastase and bovine serum albumin (BSA) were obtained from Sigma. Two different thrombin preparations (product no. T6884, 2000 units $/ \mathrm{mg}$ of protein and T3010, 4000 units/mg of protein) were used in this study. Recombinant human tissue plasminogen activator (rh-tPA) was a gift from Genentech Inc. (San Francisco, CA, USA). Human plasminogen was prepared as described previously ${ }^{25,26,31}$ by the method of
Deutsch and Mertz. $^{32} P$. aeruginosa elastase and alkaline proteinase were purchased from Nagase Biochemicals Ltd (Fukuchiyama, Japan). Benzamidine and arginine were obtained from Sigma and leupeptin and antipain from Peninsula Laboratories (San Francisco, CA, USA). The thrombin inhibitor, recombinant hirudin, was the gift of Ciba Geigy Corp. (Switzerland). Medium M9 was formulated as described previously. ${ }^{33}$ It contained $\mathrm{NH}_{4} \mathrm{Cl} 1.0 \mathrm{~g}$, $\mathrm{Na}_{2} \mathrm{HPO}_{4} 3.0 \mathrm{~g}, \mathrm{KH}_{2} \mathrm{PO}_{4} 1.5 \mathrm{~g}, \mathrm{NaCl} 2.5 \mathrm{~g}, \mathrm{MgSO}_{4}$ $0.05 \mathrm{~g}$ and glucose $0.5 \%$ in $1 \mathrm{~L}$ of distilled water.

\section{Culture conditions}

The micro-organisms were grown overnight in M9 medium in a shaking water bath at $37^{\circ} \mathrm{C}$ and then inoculated into $2 \mathrm{ml}$ of $\mathrm{M} 9$ medium in $17 \times 100-\mathrm{mm}$ tissue-culture tubes or 50 - $\mathrm{ml}$ culture tubes (Falcon). The $\mathrm{OD}_{550}$ of the cultures was determined and dilutions to $0.01 \mathrm{OD}_{550}$ were performed in sterile $\mathrm{M} 9$ medium. Depending on the experiment and organism investigated, further dilutions (1 in 10-1 in 200) of the $0.01 \mathrm{OD}_{550}$ suspension were used as the starting inoculum of organisms. Additions of proteinases or inhibitors were made before incubating the bacteria. Cultures were set up in duplicate or triplicate for each time point. The cultures were then incubated statically in a water bath at $37^{\circ} \mathrm{C}$ with the lids of the culture tubes sealed to block air exchange. These oxygenlimited conditions may mimic the in-vivo burn environment ${ }^{1}$ more closely than vigorous shaking conditions. At the end of the experiments, the $\mathrm{OD}_{550}$ was determined and, in most experiments, quantitative bacteriology was performed on serial dilutions by culture on appropriate agar plates. Colonies were counted after incubation for $24-48 \mathrm{~h}$ at $37^{\circ} \mathrm{C}$.

\section{Statistical analysis}

Reported values are expressed as the mean and SD. Statistical analysis of differences between groups was determined by Student's $t$ test or ANOVA, with the Epistat software package.

\section{Results}

Influence of $U K$ on the growth of $P$. aeruginosa strain M2

$P$. aeruginosa strain M2 cultured in M9 medium under static conditions led to only modest growth by $24 \mathrm{~h}$ (fig. 1). However, addition of UK to the medium led to a dose-dependent enhancement of growth as assessed by an increase in the $\mathrm{OD}_{550}$ of the cultures (fig. 1) and colony counts (data not shown). In the three experiments depicted in fig. 1 (panels $a, b$ and $c$ ), addition of 250-12500 units of UK led to significant enhancement of growth $(\mathrm{p}<0.05-\mathrm{p}<0.001)$. This 
Table Proteinases and proteinase inhibitors ineffective in modulating the growth of $P$. aeruginosa strain M2

\begin{tabular}{ll}
\hline Panel A: Proteinases & Panel B: Proteinase inhibitors* \\
\hline Units DFP-UK 5000-20000 & Benzamidine 0.1-10 mM \\
Recombinant human tissue plasminogen activator & Leupeptin 10-100 $\mu \mathrm{g}$ \\
$1-100 \mu \mathrm{g}$ & $\begin{array}{l}\text { Antipain } 10-100 \mu \mathrm{g} \\
\text { Human plasminogen ( } \pm 5 \text { Units UK) } 25-100 \mu \mathrm{g}\end{array}$ \\
& Arginine 1-10 mg \\
Human neutrophil elastase $1-40 \mu \mathrm{g}$ & Hirudin (thrombin inhibitor) \\
Human trypsin 1-40 $\mu \mathrm{g}$ & $1-50 \mu \mathrm{g}$ \\
Human chymotrypsin 1-40 $\mu \mathrm{g}$ & \\
Human thrombin 1-50 Units & \\
Pseudomonas elastase 5-50 $\mu \mathrm{g}$ & \\
Pseudomonas alkaline protease 5-50 $\mu \mathrm{g}$ &
\end{tabular}

* Preliminary experiments revealed that these inhibitors could inhibit UK or thrombin when incubated in sterile M9 medium.

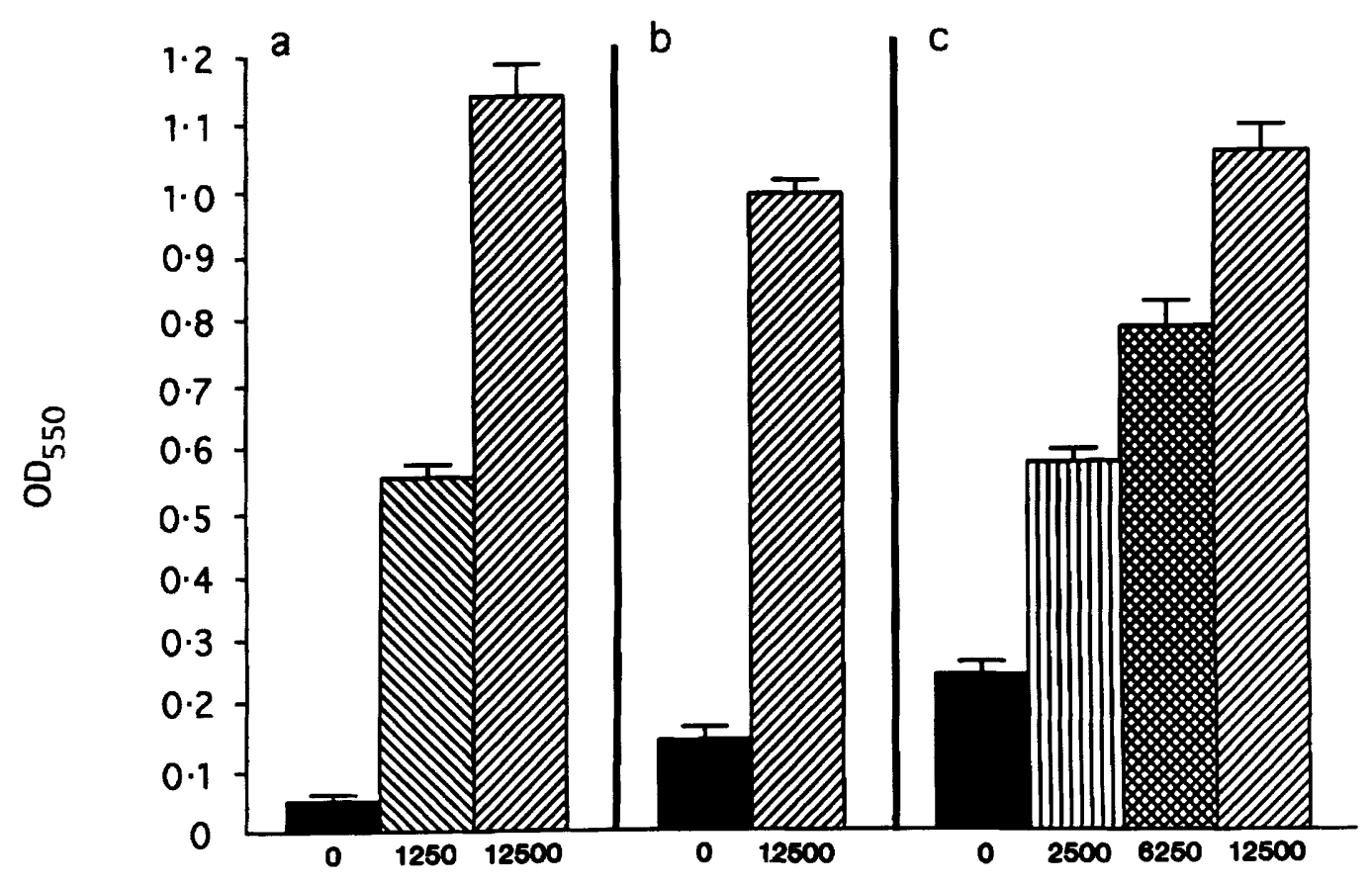

Abbokinase concentration (units)

Fig. 3. Enhancement of the growth of $P$. aeruginosa strains 44.821 , PAO and DG-1 by UK. The bacteria were cultured for $24 \mathrm{~h}$ at $37^{\circ} \mathrm{C}$ in medium M9 with or without the indicated concentrations of commercial UK. After $24 \mathrm{~h}$, the $\mathrm{OD}_{550}$ was determined. The organisms, 44.821 (panel a), PAO (panel b) and DG-1 (panel c) were cultured in triplicate and the indicated values represent the mean and SD at each point.

range of UK doses was chosen for the initial experiments because similar doses influence in-vivo $P$. aeruginosa infections in a rat chronic pulmonary infection model. ${ }^{30}$ Enhancement of bacterial growth by both UK purified by affinity chromatography and by rhUK was also observed (fig. 1, panels $\mathrm{d}$ and e).

Further experiments showed that even lower doses of UK were effective in enhancing bacterial growth, particularly when very small inocula were used. As depicted in fig. 2 (panel a), with a small starting inoculum of $P$. aeruginosa strain M2 (1 in 200 dilution of a $0.01 \mathrm{OD}_{550}$ suspension) and only 100 units of UK, enhancement of bacterial growth could be detected after $24 \mathrm{~h}$. An enhancement of bacterial growth by as little as 10 units of UK could be detected when the time of culture was extended to $30 \mathrm{~h}$ (fig. 2, panel a). By $48 \mathrm{~h}$, there was a tendency for the UK enhancement of growth to be less evident, primarily because the growth of the control cultures became more substantial (fig. 2, panel b).

Evidence that the enzymic activity of UK was required for the enhancement of bacterial growth was obtained from experiments with inactivated UK. Diisopropylfluorophosphate-inactivated UK did not stimulate bacterial growth when 5000-20000 units were tested (table). Furthermore, 1-100 $\mu \mathrm{g}$ of rh-tPA, 


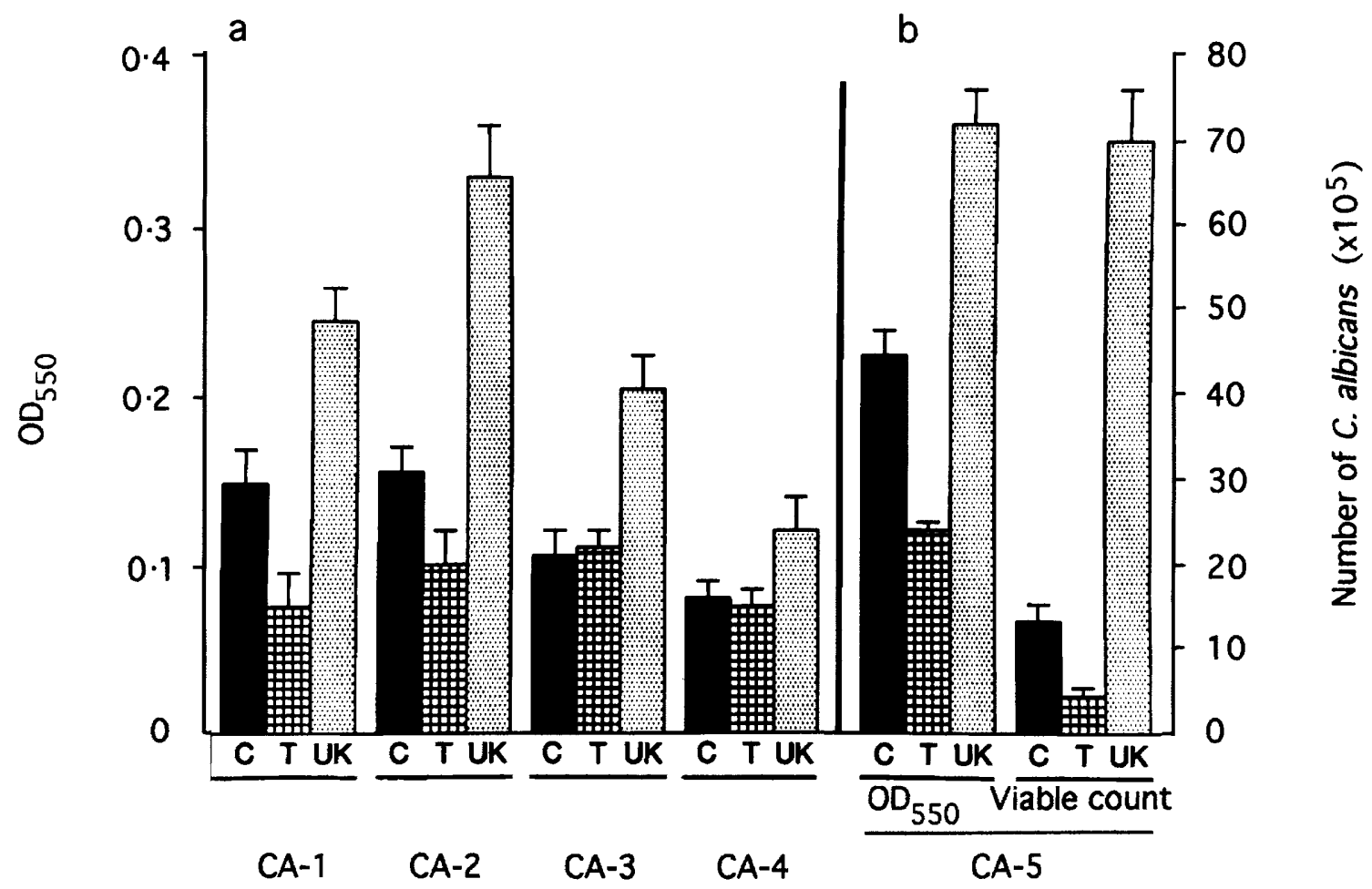

Fig. 4. Influence of UK on the growth of five clinical isolates of $C$. albicans, CA-1-CA-5, cultured in triplicate with or without (C) 10000 units of UK or 50 units of thrombin (T) for $24 \mathrm{~h}$ at $37^{\circ} \mathrm{C}$. After $24 \mathrm{~h}$, the $\mathrm{OD}_{550}$ of the cultures was determined (panel a) and, for CA-5 (panel b), both $\mathrm{OD}_{550}$ and quantitative $C$. albicans counts were determined. The indicated values represent the mean and SD at each point.

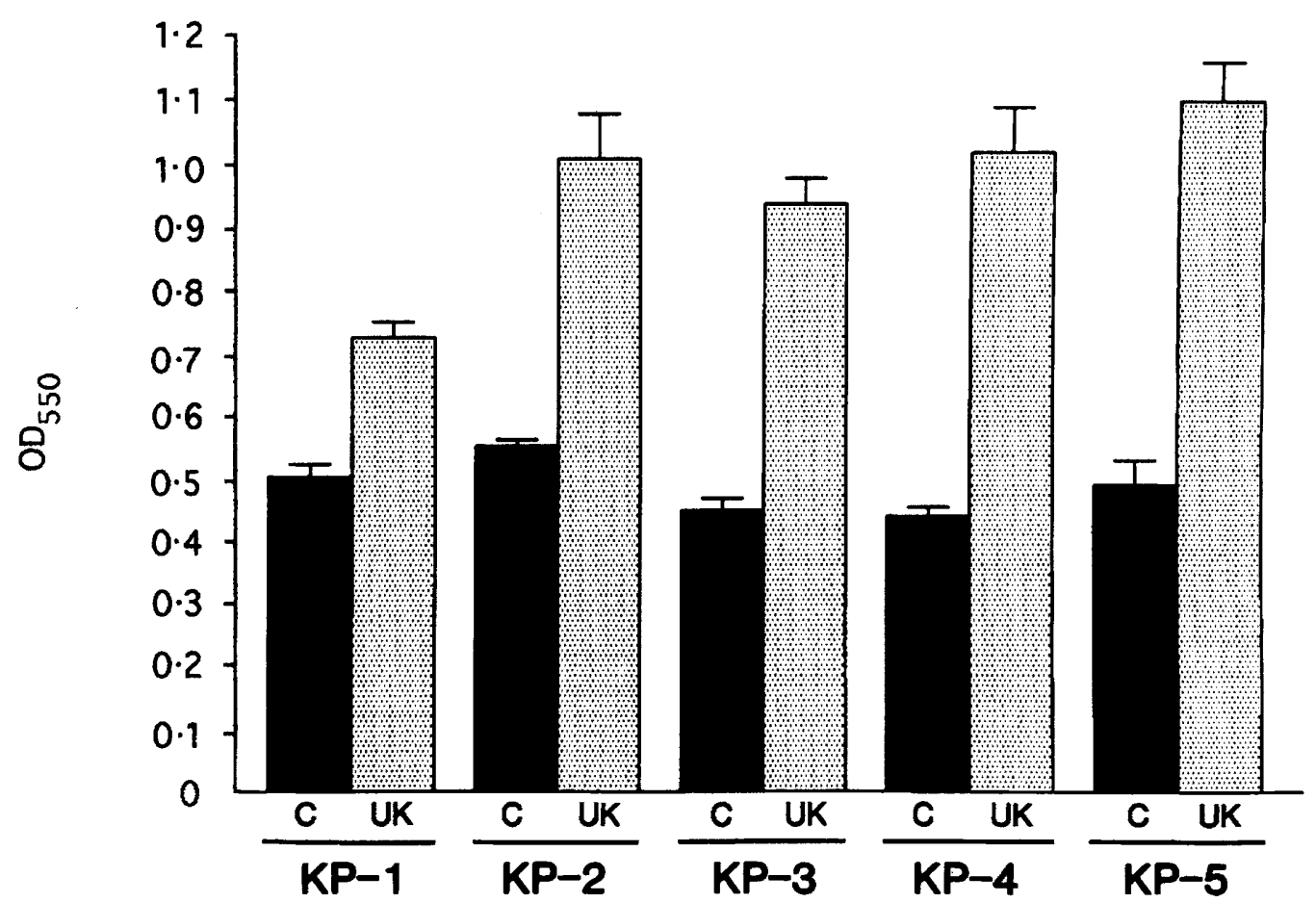

Fig. 5. Effect of UK on the growth of five clinical isolates of K. pneumoniae, KP-1-KP-5, cultured in triplicate with and without (C) 10000 units of $\mathrm{UK}$ for $24 \mathrm{~h}$ at $37^{\circ} \mathrm{C}$. The indicated values represent the mean $\mathrm{OD}_{550}$ and $\mathrm{SD}$ at each point.

a fibrinolytic enzyme that is essentially inactive in the absence of fibrin, ${ }^{24,27}$ did not enhance bacterial growth (table). Thus, the enzymic activity of UK was required for the effect on bacterial growth.
Influence of other proteinases on the growth of $P$. aeruginosa strain $M 2$

Further similar experiments indicated that the obser- 


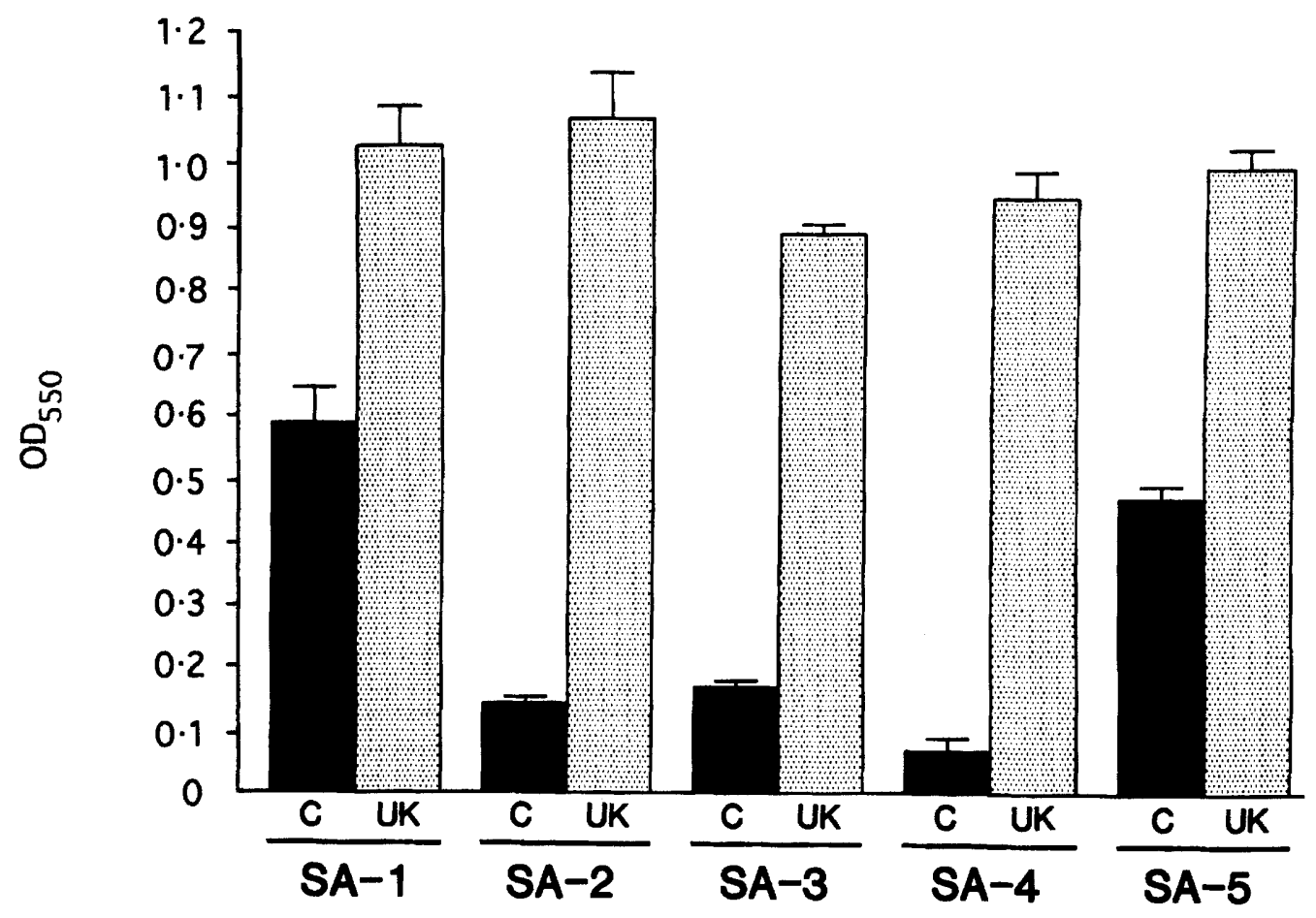

Fig. 6. Influence of UK on the growth of five clinical isolates of S. aureus, SA-1-SA-5, cultured in triplicate for 24 h at $37^{\circ} \mathrm{C}$ with and without (C) 10000 units UK. After $24 \mathrm{~h}$, the $\mathrm{OD}_{550}$ of each culture was determined. The indicated values represent the mean $\mathrm{OD}_{550}$ and $\mathrm{SD}_{\text {at }}$ each point.

ved effect of UK on the growth of $P$. aeruginosa was not given by a number of other proteinases (table). These included: plasmin, which is a lysine-specific enzyme generated by the action of UK on plasminogen ${ }^{24,27,34}$ human neutrophil elastase, which is released from activated neutrophils $;^{35}$ trypsin, which is detected in elevated concentrations in the plasma of burn patients; ${ }^{15}$ thrombin, an arginine-specific coagulation enzyme ${ }^{36}$ whose generation can be elevated during infections with gram-negative bacteria; and chymotrypsin, another pancreatic enzyme that preferentially hydrolyses linkages involving aromatic amino acids. In addition, $P$. aeruginos a elastase and alkaline proteinase, which have been implicated as virulence factors, did not stimulate directly the growth of the bacteria (table). Thus, the effect of UK on bacterial growth was not due to a general proteolysis effect.

\section{Inability of UK inhibitors to influence the growth of $P$. aeruginosa strain $M 2$}

The finding that UK could enhance the growth of strain $\mathrm{M} 2$ raised the possibility that the enzyme was performing the function of some endogenous enzyme of similar specificity which was rate limiting under the conditions of growth. There have been reports that Escherichia coli ${ }^{37}$ and Yersinia pestis ${ }^{38}$ express enzymes that can function as plasminogen activators. Therefore, strain M2 was grown in the presence of a number of compounds that can inhibit UK or other argininespecific proteinases, to determine whether they could affect bacterial growth. The compounds at the concentrations used (table), were without effect on growth when strain $\mathbf{M} 2$ was incubated under either static or vigorous shaking conditions. Therefore, the bacteria do not appear to utilise an enzyme that has exactly the same active site as UK. As the $Y$. pestis plasminogen activator has an active site different from that of $\mathrm{UK},{ }^{38}$ these findings do not completely eliminate the existence of an analogous UK-like endogenous enzyme.

\section{Influence of UK on the growth of other strains of $P$. aeruginosa}

To determine whether the effect of UK on the growth of strain M2 was unique to this strain or not, the influence of UK on the growth of a clinical isolate (strain 44.821), as well as two other laboratory strains (PAO and DG-1) of $P$. aeruginosa was assessed. As shown in fig. 3, UK enhanced the growth of all three strains of $P$. aeruginosa $(\mathrm{p}<0.01)$. Furthermore, UK enhanced the growth of variants of strain PAO (E64 and $\mathrm{B} 1$ ), deficient in alkaline protease and elastase, to the same extent as the parent PAO strain (data not shown). Therefore, the effect of UK on growth was not restricted to strain $\mathrm{M} 2$.

\section{Ability of UK to enhance the growth of other micro- organisms}

A number of other organisms besides pseudomonads commonly infect burn patients. ${ }^{1-5}$ These include C. albicans, K. pneumoniae and S. aureus. To determine whether UK could also enhance the growth of these species, five isolates of each species from burn 
patients were cultured with and without UK. As shown in fig. 4, the addition of 10000 units of UK to the $C$. albicans cultures enhanced the growth of all five strains. Similar experiments with the $K$. pneumoniae (fig. 5) and S. aureus (fig. 6) isolates gave a similar pattern of results. The degree of enhancement was variable but the pattern of enhancement was reproducible with these three organisms. The same pattern of stimulation of growth was obtained when these experiments were repeated with purified UK (data not shown). As found previously with $P$. aeruginosa, thrombin did not stimulate growth of $C$. albicans (fig. 4), K. pneumoniae or $S$. aureus (data not shown). From these experiments, it would appear that UK can enhance the growth of several organisms which commonly infect burn patients.

\section{Influence of $P$. aeruginosa proteinases on the in-vitro growth of clinical isolates of $C$. albicans}

Neely and co-workers ${ }^{9}$ reported that $P$. aeruginosa proteinases or pre-infection of burned mice with $P$. aeruginosa increased the susceptibility of such mice to $C$. albicans infection. To determine whether this phenomenon was due to a direct effect of the pseudomonal proteinases on the growth of Candida spp., purified enzymes were added to cultures of the clinical isolates of $C$. albicans. In three experiments with 1-50 $\mu \mathrm{g}$ of purified $P$. aeruginosa elastase or alkaline proteinase, there was no detectable effect on the invitro growth of the five strains of C. albicans (data not shown). This finding was obtained irrespective of whether the organisms were grown under shaking or static conditions. Therefore, these results indicate that the effect of pseudomonal proteinases on candidal infections in burned mice may be indirect.

\section{Discussion}

The results of this study support the conclusions of Holder and Neely, 10,21-23 that host proteinases may contribute to the infectious process that can occur in immunocompromised patients with thermal injuries. They indicate that a specific host proteinase, UK, one of the two primary fibrinolytic enzymes of mammals, ${ }^{24,27,34}$ can stimulate uniquely the in-vitro growth of micro-organisms which commonly infect burn patients under oxygen-limited static conditions.

In contrast to tissue plasminogen activator (tPA), which is the primary fibrinolytic enzyme of the vasculature, ${ }^{24,27} \mathrm{UK}$ is the primary plasminogen activator in connective tissues, ${ }^{24}$ including skin, ${ }^{39}$ and is expressed by inflammatory cells such as macrophages and polymorphonuclear leucocytes. ${ }^{25,26}$ Thus, the enzyme could be released from tissues following thermal injury or as a consequence of inflammatory cells being attracted to the site of injury. As UK does not depend on the presence of fibrin for activity, that present in the wound could influence the growth of a micro-organism in the burn site. The results indicate that UK enhanced the growth of micro-organisms under hypoxic conditions and especially when initially present in low numbers. These are the conditions likely to be present initially at a burn site. ${ }^{1}$ Thus, UK in the injury site could contribute to the establishment of the infection locally.

The finding that TPA was without effect in the absence of fibrin supports the conclusion that enzyme activity is required for the effect on the growth of micro-organisms. However, this does not mean that tPA could not contribute to growth in vivo when fibrin is present. It is likely that fibrin is deposited in the burn site and, therefore, endogenous tPA could become activated. However, since UK and TPA have some differences in their active sites, ${ }^{40}$ the effect of active tPA on the growth of micro-organisms remains to be confirmed. Irrespective of whether or not tPA can stimulate bacterial growth, the finding that UK uniquely potentiated growth raises some interesting questions regarding the mechanism(s) by which the enzyme exerts this effect.

UK activates plasminogen by cleaving an arg-val bond.$^{34}$ In addition, the enzyme can cleave arg-ala and arg-thr bonds in fibronectin, ${ }^{41}$ as well as activate diphtheria toxin in vitro by cleaving an arg-arg bond. ${ }^{42}$ Therefore, it is likely that the protein substrate for UK involves an $\arg -\mathrm{X}$ bond. The finding that thrombin, another enzyme which cleaves various peptide bonds involving arginine (e.g., arg-val, arg-gly, arg-cys) ${ }^{36}$ did not affect growth indicates again that the effect of UK is unique and that a specific substrate(s) is involved.

Furthermore, because UK (Abbokinase) has a mol. wt of c. $33 \mathrm{kDa}$, it is likely that the candidate substrate(s) on the micro-organisms is either exposed on the cell surface or secreted. As UK stimulated the growth of gram-negative and gram-positive bacteria and a yeast, the substrate(s) must be either very similar or common to these micro-organisms or the cleavage site(s) must be conserved. At the present time, we are not aware of any candidate substrate(s) that is involved in cell growth and which would fulfil these criteria. However, investigations are being made to identify such substrates.

The excellent technical assistance of Carol Reno, the secretarial assistance of Judy Crawford, the gift of some of the microbial strains by Dr A. McManus, the supply of UK and derivatives by $\mathrm{Dr} \mathbf{J}$. Henkin (Abbott Laboratories; Abbott Park, IL, USA) and the helpful review of the manuscript by Drs I. Holder and A. Neely (Shriners Burn Unit and the University of Cincinnati, Cincinnati, $\mathrm{OH}, \mathrm{USA}$ ) are acknowledged with gratitude. This investigation was supported by grants from Abbott Laboratories and the Canadian Cystic Fibrosis Foundation. 


\section{References}

1. Deitch E. The management of burns. $N$ Engl J Med 1990; 323: 1249-1253.

2. Pruitt BA. Infection: a cause or effect of pathophysiologic change in burn and trauma patients. In: Paubert-Braquet $M$ (ed) Lipid mediators in the immunology of shock. New York, Plenum Press. 1986: 31-42.

3. Muir FK, Barclay TL, Settle JAD. Burns and their treatment, 3rd edn. London, Butterworths. 1987.

4. Alexander JW. The role of infection in the burn patient. In Boswick JA (ed) The art and science of burn care. Rockville, Aspen Publishers. 1987: 103-121.

5. Demling RH, LaLonde $\mathrm{C}$ (eds). Burn trauma. New York, Thieme Medical Publishers. 1989.

6. Gianotti L, Alexander JW, Pyles T, James L, Babcock GF. Relationship between extent of burn injury and magnitude of microbial translocation from the intestine. J Burn Care Rehabil 1993; 14: 336-342.

7. Epstein MD, Banducci DR, Manders EK. The role of the gastrointestinal tract in the development of burn sepsis. Plast Reconstr Surg 1992; 90: 524-531.

8. Holder IA, Neely AN. Combined host and specific antiPseudomonas-directed therapy for Pseudomonas aeruginosa infections in burned mice: experimental results and theoretical considerations. J Burn Care Rehabil 1989; 10: 131-137.

9. Neely AN, Law EJ, Holder IA. Increased susceptibility to lethal Candida infections in burned mice preinfected with Pseudomonas aeruginosa or pretreated with proteolytic enzymes. Infect Immun 1986; 52: 200-204.

10. Holder IA, Neely AN. The role of proteases in Pseudomonas infections in burns: a current hypothesis. Antibiot Chemother 1991; 44: 99-105.

11. Drost AC, Burleson DG, Cioff WG, Mason AD, Pruitt BA. Plasma cytokines after thermal injury and their relationship to infection. Ann Surg 1993; 218: 74-78.

12. Bjornson AB, Somers SD. Down-regulation of chemotaxis of polymorphonuclear leukocytes following thermal injury involves two distinct mechanisms. J Infect Dis 1993; 168 120-127.

13. Dong YL, Abdullah K, Yan TZ et al. Effect of thermal injury and sepsis on neutrophil function. J Trauma 1993; 34 : 417-421.

14. Kowal-Vern A, Gamelli RL, Walenga JM, Hoppensteadt D, Sharp-Pucci M, Schumacher HR. The effect of burn wound size on hemostasis : a correlation of the hemostatic changes to the clinical state. $J$ Trauma 1992; 33: 50-57.

15. Deby-Dupont G, Faymonville M, Pincemail J et al. Trypsinlike activity in burn and sepsis. In: Paubert-Braquet $M($ ed) Lipid mediators in the immunology of shock. NATO ASI Series. $1989 ; 139: 227-235$.

16. Neely AN, Nathan P, Highsmith RF. Plasma proteolytic activity following burns. $J$ Trauma 1988; 28: 362-367.

17. Ruud TE, Kierulf P, Godal HC, Aune S, Aasen AO. Studies on pathological plasma proteolysis in severely burned patients using chromogenic peptide assays: a preliminary report. Adv Exp Med Biol 1984; 167: 449-454.

18. Holder IA, Neely AN. Pseudomonas elastase acts as a virulence factor in burned hosts by Hageman factor-dependent activation of the host kinin cascade. Infect Immun 1989; 57: $3345-3348$

19. Holder IA. Pseudomonas immunotherapy. Serodiagn Immunother Infect Dis 1988; 2: 7-16.

20. Khan MM, Yamamoto T, Araki H, Shibuya Y, Kambara T. Role of Hageman factor/kallikrein-kinin system in pseudomonal elastase-induced shock model. Biochim Biophys Acta 1993; 1157: 119-126.

21. Holder IA, Neely AN. Hageman factor dependent activation and its relationship to lethal Pseudomonas aeruginosa burn wound infections. Agents Actions 1992; Suppl 38: 329-342.

22. Holder IA, Neely AN. Hageman factor-dependent kinin activation in burns and its theoretical relationship to postburn immunosuppression syndrome and infection. J Burn Care Rehabil 1990; 11 : 496-503.

23. Holder IA. Experimental studies of the pathogenesis of infections due to Pseudomonas aeruginosa: effect of treatment with protease inhibitors. Rev Infect Dis 1983; 5 Suppl 5: S914-S921.

24. Hart DA. Regulation of plasminogen activators in connective tissues: potential for thrombolytic therapy in collagenvascular diseases. Fibrinolysis 1992; 6 Suppl 1: 43-48.

25. Arndt AD, Gohill J, Rankin K, Houwen B, Hart DA Differentiation-linked expression of the plasminogen activator inhibitor type 2 gene in the human HL-60 promyelocytic cell line. Exp Cell Res $1989 ; 185$ : 473-481.

26. Rehemtulla A, Arndt A, Hart DA. Induction of plasminogen activator inhibitor type 2 expression during differentiation of human K562 cells towards a macrophage phenotype. Biochem Cell Biol 1990; 68: 1337-1343.

27. Hart DA, Rehemtulla A. Plasminogen activators and their inhibitors: regulators of extracellular proteolysis and cell function. Comp Biochem Physiol B 1988; 90: 691-708.

28. Stieritz DD, Holder IA. Experimental studies of the pathogenesis of infections due to Pseudomonas aeruginosa: description of a burned mouse model. J Infect Dis 1975; 131: 688-691.

29. Snell K, Holder IA, Leppla SA, Saelinger CB. Role of exotoxin and protease as possible virulence factors in experimental infections with Pseudomonas aeruginosa. Infect Immun $1978 ; 19: 839-845$.

30. Hart DA, Green F, Whidden P, Henkin J, Woods DE. Exogenous rh-urokinase modifies inflammation and Pseudomonas aeruginosa infection in a rat chronic pulmonary infection model. Can J Microbiol 1993; 39: $1127-1134$.

31. Cieplak W, Hart DA. Formation of stable complexes between urokinase and a human urinary component. Thromb Haemost $1985 ;$ 53: 36-41.

32. Deutsch DG, Mertz ET. Plasminogen: purification from human plasma by affinity chromatography. Science 1970; 170: 1095-1096.

33. Roberts RB, Abelson PH, Cowie DB, Bolton ET, Britten RJ. Studies of biosynthesis in Escherichia coli. Washington, DC, Carnegie Institute of Washington Publication. 1963: 607.

34. Christman J, Silverstein S, Acs G. Plasminogen activators. In: Barrett AJ (ed) Proteinases in mammalian cells and tissues. Amsterdam, North-Holland. 1977: 91-149.

35. Murphy P, Hart DA. Regulation of enzyme release from human polymorphonuclear leukocytes: further evidence for the independent regulation of granule subpopulations. Biochem Cell Biol 1987; 65: 1007-1015.

36. Lundblad RL, Kingdon HS, Mann KG. Thrombin. Proteolytic enzymes part B. Methods Enzymol 1976; XLV: 156-176.

37. Leytus SP, Bowles LK, Konisky J, Mangel WF. Activation of plasminogen to plasmin by a protease associated with the outer membrane of Escherichia coli. Proc Natl Acad Sci USA 1981; 78: 1485-1489.

38. Sodeinde OA, Subrahmanyan YV, Stark K, Quan T, Bao Y, Goguen JD. A surface protease and the invasive character of plague. Science 1992; 258: 1004-1007.

39. Chen CS, Lyons-Giordano B, Lazarus GS, Jensen PJ. Differential expression of plasminogen activators and their inhibitors in an organotypic skin coculture system. $J$ Cell Sci 1993; 106: 45-53.

40. Geiger M, Binder BR. Tissue-type plasminogen activator and urokinase: differences in the reaction pattern with the active-site titrant 4-methylumbelliferyl-p-guanidinobenzoate hydrochloride. Biochim Biophys Acta 1987; 912: $34-40$.

41. Gold LI, Rostagno A, Frangione B, Passalaris T. Localization of the cleavage sites on fibronectin following digestion by urokinase. J Cell Biochem 1992; 50: 441-452.

42. Cieplak W, Eidels L. Specific cleavage of diphtheria toxin by a plasminogen activator. In: Bonivida B, Collier R (eds) Membrane-mediated cytotoxicity UCLA symposia on molecular and cellular biology, New Series. New York, Alan R. Liss. 1987: 19-26. 